\title{
Economic Feasibility of Echelon Utilization Battery in Photovoltaic Energy Storage
}

\author{
Yibin $\mathrm{Tao}^{1}$, Jinhua Xue ${ }^{1}$, Min $\mathrm{Xia}^{2}$, Jin Tao ${ }^{2}$, Qichao Zhang ${ }^{3,}, \mathrm{Xiao} \mathrm{Li}^{3}$, Qiangqiang $\mathrm{Liao}^{3}$, $\mathrm{Cheng} \mathrm{Li}^{4}$ and Haibo Tang ${ }^{5}$ \\ ${ }^{1}$ Nanjing Branch of China Electric Power Research Institute, Nanjing 210003, China \\ ${ }^{2}$ Wuhu Mingyuan Electric Power Engineering Consulting Design Co., Ltd, Wuhu 241000, China \\ ${ }^{3}$ Shanghai Key Laboratory of Materials Protection and Advanced Materials in Electric Power, Shanghai Engineering Research Center of \\ Electric Energy Conversion, Shanghai University of Electric Power, Shanghai 200090, China \\ ${ }^{4}$ State Grid Hanzhong Electric Power Supply Company, Hanzhong 723000, China \\ ${ }^{5}$ Shanghai Xiaochuan Technology Co., Ltd., Shanghai 200082, China
}

\begin{abstract}
Taking the power load of an industrial park in Shanghai as an example in this paper, particle swarm optimization and cost-benefit model are employed to analyse the economy of new lithium-ion batteries, echelon lithium-ion batteries and lead-carbon batteries in photovoltaic energy storage systems in the whole life cycle. The research results showed that the economic order from large to small among different batteries in the photovoltaic energy storage system was new lithium-ion battery, echelon utilization lithium-ion battery and lead-carbon battery. The declines in energy storage cost and discount rate and the rise in peak electricity price can greatly improve the net present value of a photovoltaic-energy storage system (PV-BES) system.
\end{abstract}

\section{Introduction}

By the end of 2019, the installed capacity of photovoltaic power generation in Shanghai has exceeded $1 \mathrm{GW}$. It is worth noting that if the unstable photovoltaic factors are introduced into the stable power grid system on a large scale, the safe and stable operation of the power grid will be affected [1]. For example, when the uncontrollable photovoltaic is connected to the distribution network of residential quarters, there will be voltage fluctuation, flicker, reverse power flow and other problems. Therefore, battery energy storage system is a necessary technical solution. Although it is expensive for most families, it has more advantages than disadvantages as a buffer pool for variable photovoltaic power [2]. The echelon use of retired electric vehicles batteries is considered as one of the most promising ways to reduce battery cost by extending their service life [3]. In this study, the profit of pv-bes hybrid system is evaluated based on battery type, energy storage cost, discount rate and peak price. The evaluation results have important guiding significance for the further development of photovoltaic and bes industries.

\section{Methodology and parameters}

Photovoltaic system and battery energy storage system constitute a whole. The power consumption of the hybrid system includes first providing photovoltaic power to the load; the surplus energy is stored in the bes system and then sent to the grid. If photovoltaic power generation is insufficient, the energy stored in BES will be provided to the load first, rather than to the grid power supply. The batteries used in BES systems include new lithium ion (Li-ion), second lithium ion ( $\mathrm{Li}_{-1}$ ion $_{2 \mathrm{nd}}$ ) and lead-carbon $(\mathrm{Pb}-\mathrm{C})$. Cost-benefit models for a PV-BES system and case study definition refer to the literature [4]. The parameter settings for different BES systems are shown in Table 1.

Table 1. Parameter settings for different BES systems.

\begin{tabular}{cccc}
\hline Battery types & Li-ion & Li-ion $_{2 \text { nd }}$ & $\mathrm{Pb}-\mathrm{C}$ \\
\hline SOC $_{\min }(\%)$ & 10 & 10 & 40 \\
\hline SOC $_{\max }(\%)$ & 90 & 90 & 100 \\
\hline Lifetime (years) & 10 & 5 & 5 \\
\hline $\begin{array}{c}\text { Round-trip } \\
\text { efficiency (\%) }\end{array}$ & 92 & 88 & 80 \\
\hline $\begin{array}{c}\text { Unit cost } \\
(¥ / \mathrm{kWh})\end{array}$ & 1800 & 200 & 1200 \\
\hline
\end{tabular}

\section{Results and discussion}

\subsection{Net Present Value Analysis}

For comparative analysis, particle swarm optimization (PSO) is used to optimize the NPV of distributed PVBES system with different BES (such as lithium-ion battery, lithium-ion battery and lead-carbon battery), as shown in Fig. 1, The results show that the NPV of distributed photovoltaic systems with different BES structures decreases in turn ( $\mathrm{Li}$-ion $>$ Li-ion 2 nd $>\mathrm{Pb}-\mathrm{C})$.

\footnotetext{
* Corresponding author: $444674975 @$ qqq.com
} 


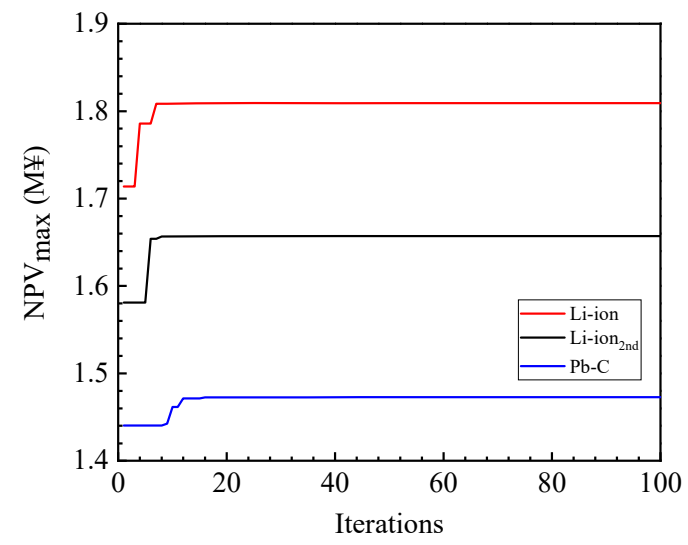

Fig. 1. The convergence curve of $\mathrm{NPV}_{\max }$ of distributed photovoltaic system based on PSO algorithm..

\subsection{Influencing Factors of NPV}

\subsubsection{Battery cost.}

Figure 2 shows the relationship between the NPV of PVBES system with different batteries and the battery cost. The red dot at the bottom of each line in figure 2 represents the net present value of the PV-BES system in the current situation. NPV increases linearly with the decrease of battery cost, and Li-ion BES shows the maximum return of these three BES. The NPVs of Liion $_{2 \text { nd }}$ is more than that of $\mathrm{Pb}-\mathrm{C}$. Two decisive elements leading to low NPV of Pb-c-BES are shallow charge and discharge depth and low cycle life.

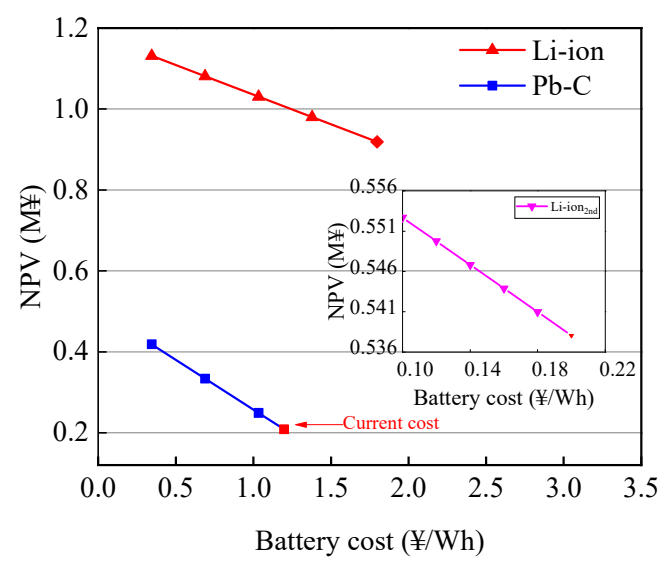

Fig. 2. Relationship of the NPV of a PV-BES system with different batteries with battery cost.

\subsubsection{Discount rate.}

Figure 3 shows the relationship between NPV and discount rate of PV-BES system with different batteries. At present, the discount rate is set at 0.08 , as shown in the red vertical bar in Figure 3. It can be seen from Figure 3 that with the decrease of discount rate, the NPV of PV-BES system increases greatly; the NPV of PVBES system will be doubled when the discount rate is reduced from 0.08 to 0.03 .

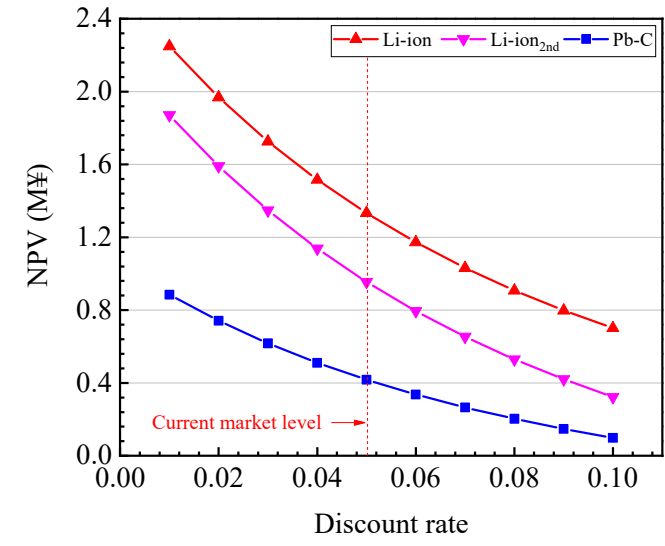

Fig. 3. Relationship of the NPV of a PV-BES system with different batteries with discount rate.

\subsubsection{Peak electricity price.}

Generally speaking, the valley price is close to the cost of coal-fired power plants. Therefore, peak shaving price is a very advantageous scheme to balance power supply and demand and improve equipment utilization. Figure 4 shows the relationship between NPV and peak price of PV-BES system. In the current situation, the peak price is $1.106 ¥ / \mathrm{kWh}$, as shown by the red vertical bar in Figure 4. Under the same growth rate of peak electricity price, Li-ion and $\mathrm{Li}_{-1} \mathrm{in}_{2 n d} \mathrm{BESs}$ can generate more profits than lead-carbon battery.

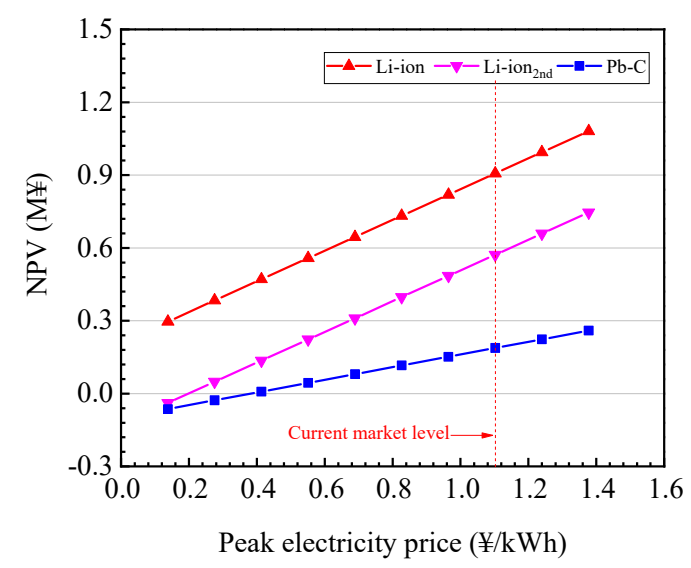

Fig. 4. Relationship of the NPV of a PV-BES system with different batteries with peak electricity price.

\subsubsection{Energy storage subsidy.}

Without the government's stimulus policy and financial support, it is impossible to cultivate and popularize a new technology. The prosperity of China's photovoltaic and wind power industries is an impressive example of active government support, such as subsidies for these types of energy [5]. By the end of 2017, China's cumulative installed capacity of photovoltaic and wind power reached $130 \mathrm{gw}$ and $188 \mathrm{gw}$ respectively, ranking first in the world. Therefore, the impact of government stimulus policies on the energy storage industry is 
emerging. Among all the government stimulus policies, the energy storage subsidy policy is often hotly discussed. Two schemes are proposed: one is to subsidize the energy storage according to the initial installed capacity of the BES system; the other is to subsidize the energy storage according to the energy release during the operation of the BES system. However, the specific level of energy storage subsidies has not been determined.

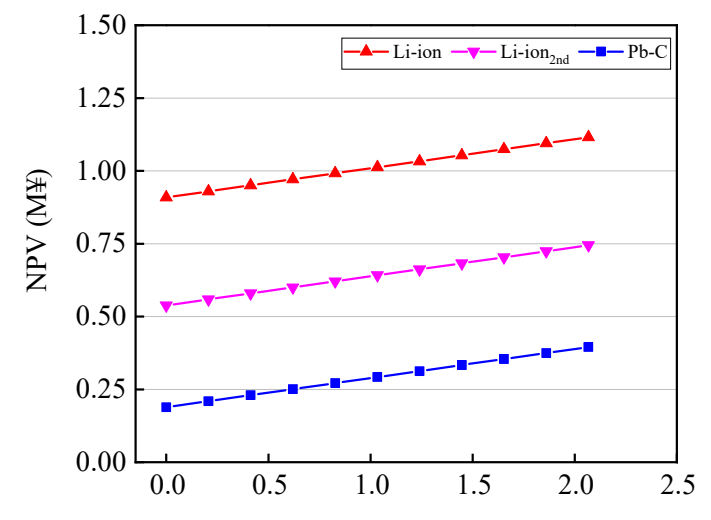

BES subsidy based on installation capacity ( $¥ / \mathrm{kWh})$

Fig. 5. Relationship of the NPV of a PV-BES system with different batteries with BES subsidy based on installation capacity.

Figures 5 and 6 respectively illustrate the dependence of NPV of PV bes systems using different batteries on BES subsidies based on installed capacity and energy released during operation. As can be seen from Figure 5, based on the installed capacity of the four bes systems, the NPV of PV-BES system increases in equal proportion to the increase of BES subsidies. However, the effect of BES subsidy based on discharge energy on NPV of PV-BES system is significantly different as shown in Fig. 6. The NPV of both Li-ion BES and Li-ion 2nd $\mathrm{BES}$ distributed systems is more than that of $\mathrm{Pb}-\mathrm{C}$ BES. Among the four BES systems, Pb-C-BES shows that the growth rate of the same BES subsidy based on discharge energy is the lowest. The difference of energy storage subsidy benefits among different bes may be one of the reasons that detailed energy storage subsidy bill has not yet been issued. Most investors in the energy storage industry seem to prefer to invest in BES subsidies based on the initial installed capacity, because this will relieve the pressure on their capital pool to some extent.The BES subsidy based on the energy emitted during the operation period can not maximize the benefits of $\mathrm{Pb}-\mathrm{C} \mathrm{BES}$, and the income growth rate under the BES subsidy is the lowest. Managers of government departments are more willing to promote the second act from the perspective of process management. In fact, the second motion is more reasonable than the first because the allowance in the second motion can be used for more work and encourage more work than the allowance in the first motion. In addition, in the second motion, the battery technology with high cost performance is preferred, because high performance Li-ion and $\mathrm{Li}_{-1}$ ion $_{2 \mathrm{nd}}$ $\mathrm{BES}$ will generate more profits than $\mathrm{Pb}-\mathrm{C}$ BES.

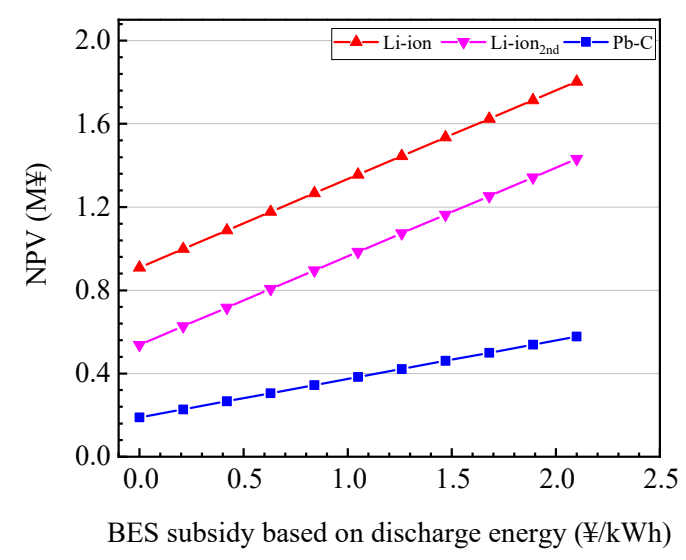

Fig. 6. Relationship of the NPV of a PV-BES system with different batteries with BES subsidy based on energy discharged during operation period.

\section{Conclusions}

(1) The NPV of distributed photovoltaic systems with different BES structures decreases in turn (Li-ion $>$ Liion $_{2 n d}>\mathrm{Pb}-\mathrm{C}$ ), due to the characteristics of these batteries.

(2) The declines in energy storage cost and discount rate and the rise in peak electricity price can greatly improve the net present value of a PV-BES system.

(3) Based on the generation and growth rate of these photovoltaic power generation systems, the generation of these power generation systems increases in the same proportion. The second bill on BES subsidies is more beneficial to the BES industry than the first one, because the implementation of the second bill can obtain more jobs and higher remuneration.

(4) The use of echelon battery in photovoltaic energy storage can not only prolong the service life of electric vehicle battery, but also greatly reduce the cost of photovoltaic power generation system.

\section{Acknowledgment}

This work was sponsored by the Open Fund of Jiangsu Engineering Research Centre of Power Conversion and Application (China Electric Power Research Institute) (5242001700DM-C), China.

\section{References}

1. J Yaghoobi, M Islam and N Mithulananthan. APPL ENERG 211 358-367 (2018).

2. AB Gallo, JR Simões-Moreira, HKM Costa, MM Santos. RENEW SUST ENERG REV 65 800-822 (2016).

3. X Han, Y Liang,Y Ai and J Li. ENERGY 165326 (2018)

4. Q Liao,Y Zhang, Y Tao,J Ye,C Li. INT J ENERG RES 43 6461-6474 (2019).

5. $\mathrm{X}$ Zhao, Y Zeng, D Zhao. ENERGY 88 572583(2015) 